\title{
EFICÁCIA DE HERBICIDAS DE MANEJO NO CONTROLE DE Richardia brasiliensis EM SEMEADURA DIRETA NA CULTURA DO FEIJOEIRO
}

\author{
Luiz Alberto Kozlowski ${ }^{1}$ \\ 'Eng ${ }^{0}$. Agrônomo, MSc., Professor Adjunto. Faculdade de Agronomia, Pontifícia Universidade Católica do Paraná. kozlowsk@ @la01.pucpr.br
}

\section{RESUMO}

O sistema de plantio direto, caracterizado pela presença de cobertura morta sobre a superfície do solo, provoca algumas alterações na dinâmica da flora infestante, como a diminuição das espécies anuais e aumento de algumas espécies perenes, assim como o surgimento de plantas daninhas de difícil controle, como a Richardia brasiliensis. O objetivo do trabalho foi avaliar a eficácia de herbicidas de manejo no controle de Richardia brasiliensis e o efeito destes sobre o rendimento e componentes do rendimento do feijoeiro em plantio direto. O delineamento experimental adotado foi o de blocos ao acaso com 6 tratamentos e 4 repetições. Os tratamentos foram: sulfosate ( $878 \mathrm{~g} / \mathrm{ha}$ ), glyphosate CS ( $960 \mathrm{~g} / \mathrm{ha})$, aplicação sequiêncial de sulfosate e paraquat/diuron (627 e 200/100 g/ha), glyphosate WG (958 g/ha) e glyphosate+2,4-D (720+720 g/ ha). Foram feitas avaliações visuais da percentagem de controle na semeadura do feijoeiro e aos 7 e 18 dias depois da semeadura (DDS). Os resultados mostraram que o nível de controle da infestante no momento da semeadura foi inferior a $40 \%$ para todos os tratamentos, ao passo que aos 7 DDS foi de $72 \%$ para o sulfosate e aos 18 DDS não houve diferença significativa entre o sulfosate e glyphosate, com 80 e $75 \%$ de controle, respectivamente. Os melhores rendimentos do feijoeiro foram obtidos com sulfosate e glyphosate, que não diferiram significativamente entre si. Com relação aos componentes do rendimento, o melhor resultado para número médio de vagens por planta foi obtido com sulfosate e para os demais componentes não houve diferenças significativas entre os tratamentos.

Palavras-chave: glyphosate, plantio direto, sulfosate.

\author{
ABSTRACT \\ Efficacy of burndown herbicides in Richardia brasiliensis control in no-tillage \\ systems of common bean crop
}

No-tillage systems, characterized by presence of straw on soil surface, provoke some alteration in weed population dynamics, such as a reduction in annual species and increase in perennial species, as well as the appearence of weeds that are hard to control , such as Richardia brasiliensis. The objective of the present work was to evaluate the efficiency of burndown herbicides in Richardia brasiliensis control and their effect on yield and yield components in beans grown under no-tillage systems. The experimental design was a complete randomized block with six treatments and four replications. The treatments were: sulfosate ( $878 \mathrm{~g} / \mathrm{ha})$, glyphosate SC (960 g/ha), sequential application of sulfosate and paraquat/diuron (627 and 200/100 g/ha), glyphosate WG (958 g/ha) and glyphosate+2,4-D (720+720 g/ha). The percentage of control in bean sowing, at 7 days after the sowing (DAS) and at 18 DAS were evaluated. The results at sowing were defficient, lower than $40 \%$ for all treatments, while at 7 DAS was $72 \%$ for sulfosate and at 18 DAS there was no difference between sulfosate and glyphosate, 
with $80 \%$ and $75 \%$ of control, respectively. The best bean yields were with sulfosate and glyphosate, however there was no significant difference between them. Regarding yield components, the best results for average number of pods per plant was achieved with sulfosate and for the others components there was no difference between treatments.

Key words: glyphosate, no-till, sulfosate.

\section{INTRODUÇÃO}

A principal característica do plantio direto é o não revolvimento do solo. Em conseqüência, os resíduos das culturas anteriores, adubação verde e infestantes ficam sobre o terreno formando o que se designa por cobertura morta, que provoca alterações nas características físicas, químicas e biológicas do solo. No que diz respeito às infestantes, estas modificam a constituição qualitativa e quantitativa do complexo florístico que se desenvolve no terreno (Almeida, 1991), como a diminuição das espécies anuais e aumento de algumas espécies perenes de infestantes, assim como o surgimento de plantas daninhas de difícil controle para herbicidas de manejo e pós-emergentes, como a poaia-branca (Richardia brasiliensis) (Adegas, 1998; Lorenzi, 1984).

A operação de manejo é fundamental para o sistema de semeadura direta, pois é ela que elimina as infestantes antes da semeadura das culturas. Quando bem realizada proporciona um controle melhor em pós-emergência evitando que espécies como a poaia-branca venham causar problemas futuros, comprometendo todo o sistema de controle de plantas daninhas (Buzatti, 1999).

Após vários anos de plantio direto utilizando-se da sucessão trigo/soja e sem rotação de herbicidas, associada a manejos químicos deficientes, ocorre seleção de espécies como a poaia-branca. A ocorrência desta espécie se dá normalmente no início da primavera, geralmente na cultura do trigo ou aveia. Normalmente o cultivo do feijão vem imediatamente após a colheita do trigo ou manejo da aveia e, nestas condições, tem-se observado dificuldade no controle da poaia-branca com os tradicionais herbicidas de manejo (Oliveira, 1989).

A poaia-branca é uma das mais importantes plantas daninhas que infestam espontaneamente as áreas agrícolas do Brasil. É uma espécie anual, herbácea, prostrada, ramificada, caule densamente hirsuto, medindo $20-50 \mathrm{~cm}$ de comprimento, com reprodução por sementes e que apresenta grande vigor vegetativo, cobrindo rapidamente o solo (Lorenzi, 1991). É uma planta nativa da América do Sul, ocorrendo desde a cordilheira dos Andes até a Costa Atlântica. No Brasil, tem vasta distribuição geográfica, com maior ocorrência em regiões agrícolas do Centro-Oeste, Sudeste e Sul, sendo comum em solos de textura média, com boa umidade. Seu desenvolvimento é estimulado com boa iluminação, sendo mais agressiva em áreas com vegetação menos densa (Rosseto et al., 1997).

Esta planta daninha infesta pastagens, pomares e lavouras anuais, nas quais promove intensa interferência com- petitiva, especialmente no início do ciclo das culturas de verão. Esta espécie tem sido selecionada por herbicidas e pela adoção do sistema de semeadura direta na região sul do país (Kissmann \& Groth, 1994; Ruedell, 2000).

O objetivo deste trabalho foi avaliar a eficácia de herbicidas de manejo no controle da poaia-branca e o efeito destes sobre o rendimento e componentes do rendimento do feijoeiro em plantio direto.

\section{MATERIAL E MÉTODOS}

O trabalho experimental de campo foi conduzido na safra 1999/2000, na Fazenda Experimental Gralha Azul, da Pontifícia Universidade Católica do Paraná, município de Fazenda Rio Grande, PR. A região apresenta clima do tipo $\mathrm{Cfb}$ e solo pertencente à unidade de mapeamento associação Latossolo Vermelho-Amarelo Álico + Cambissolo Álico, com horizonte A proeminente, textura argilosa, fase sub-tropical, relevo suave ondulado.

Após as aplicações de herbicidas de manejo, foi instalada a cultura do feijoeiro na área experimental, com semeadura direta realizada em 22 de dezembro de 1999, utilizando-se a variedade de feijão 'FT Nobre', grupo comercial preto, hábito de crescimento indeterminado, tipo II, ereto, com fileiras espaçadas de $0,4 \mathrm{~m}$ entre si e 15 sementes por metro linear, com adubação de $300 \mathrm{~kg} / \mathrm{ha}$ do formulado 04-20-20. Durante o ciclo do feijoeiro foi realizado o controle químico das plantas daninhas em pós-emergência precoce (infestantes com duas folhas), com a mistura pronta do herbicida fomesafen/fluazifop-p-butil, na dose de 0,4 1/ha.

$\mathrm{O}$ delineamento experimental utilizado foi de blocos ao acaso com seis tratamentos e quatro repetições, sendo as parcelas de 2,5 m x 5,0 m (12 $\left.\mathrm{m}^{2}\right)$ com área útil de $4 \mathrm{~m}^{2}$ (1,0 $\mathrm{m} \times$ 4,0 m). Na Tabela 1, encontram-se discriminados os herbicidas testados com seus nomes comum e comercial, formulações, doses utilizadas e épocas de aplicação.

Os herbicidas foram aplicados usando-se equipamento de precisão, pressurizado com $\mathrm{CO}_{2}$, provido de barra contendo quatro pontas de jato plano em leque, Teejet XR 110.02 VS, espaçados entre si de $0,5 \mathrm{~m}$, com volume de calda de 120 1/ha e pressão de aspersão de $1,0 \mathrm{kgf} / \mathrm{cm}^{2}$. As condições ambientais no momento da aplicação dos tratamentos de manejo, realizados aos 20 dias antes da semeadura (DAS), foi de céu sem nuvens, temperatura do ar de $26^{\circ} \mathrm{C}$, umidade relativa do ar de $62 \%$ e velocidade do vento de 3 a $5 \mathrm{~km} / \mathrm{h}$. Para os tratamentos de manejo realizados aos 10 DAS, a tem- 
Eficácia de herbicidas no controle de Richardia brasiliensis

Tabela 1. Tratamentos herbicidas utilizados no experimento, com seus respectivos nomes, comum e comercial, formulações, doses e épocas de aplicação. Fazenda Experimental Gralha Azul/PUCPR. Fazenda Rio Grande, PR. 1999/2000.

\begin{tabular}{|c|c|c|c|c|c|}
\hline \multicolumn{2}{|c|}{ Herbicidas } & \multirow{2}{*}{ Formulação } & \multirow{2}{*}{$\begin{array}{l}\text { Dose } \\
\text { (g/ha) }\end{array}$} & \multirow{2}{*}{\multicolumn{2}{|c|}{$\frac{1^{a} \text { aplicação } 2^{-} \text {aplicação }}{\text { (dias antes da semeadura) }}$}} \\
\hline Nome Comum & Nome Comercial & & & & \\
\hline Sulfosate & Zapp & $\mathrm{CS}^{2}$ & $878^{5}$ & 10 & - \\
\hline Glyphosate CS & Roundup Transorb & $\mathrm{CS}$ & $960^{5}$ & 10 & - \\
\hline Sulfosate e & Zapp e & $\mathrm{CS} \mathrm{e}$ & $627 \mathrm{e}$ & 20 & - \\
\hline paraquat/diuron $^{1}$ & Gramocil & $\mathrm{SAC}^{3}$ & $200 / 100^{6}$ & - & 0 \\
\hline Glyphosate WG & Roundup WG & $\mathrm{WG}^{4}$ & $958^{5}$ & 10 & - \\
\hline Glyphosate $+2,4 \mathrm{D}$ & Roundup + DMA 806 & $\mathrm{WG}+\mathrm{SAC}$ & $720+720^{5}$ & 10 & - \\
\hline
\end{tabular}

${ }_{2}^{1}$ Foi adicionado Agral a $0,2 \%$ v/v

${ }^{2}$ Concentrado solúvel

${ }^{3}$ Solução aquosa concentrada

${ }^{4}$ Grânulos autodispersíveis em água

${ }^{5}$ Equivalente ácido

${ }^{6}$ Ingrediente ativo

peratura foi de $27^{\circ} \mathrm{C}$, umidade relativa do ar de $60 \%$ e velocidade do vento de 4 a $5 \mathrm{~km} / \mathrm{h}$. Para o tratamento de manejo seqüencial, realizado no dia da semeadura, o céu apresentava-se sem nuvens com temperatura do ar de $25^{\circ} \mathrm{C}$, umidade relativa do ar de $65 \%$ e vento entre 0 e $5 \mathrm{~km} / \mathrm{h}$.

Foram realizadas avaliações visuais da eficácia de controle da poaia-branca na semeadura do feijoeiro (antes da segunda aplicação de manejo), aos 7 dias depois da semeadura (DDS) e aos 18 DDS, utilizando-se uma escala percentual de 0 a $100 \%$, onde 0 (zero) representa nenhum controle e $100 \%$ o controle total. A poaia-branca representava $40 \%$ de cobertura da área das parcelas experimentais e encontrava-se no estádio de desenvolvimento de floração no momento da primeira aplicação de manejo, aos 20 dias antes da semeadura.

Foram avaliados também o rendimento e os componentes do rendimento (número de vagens por planta, número de grãos por vagem e massa de 100 sementes) do feijoeiro. $O$ rendimento de grãos foi avaliado a partir da colheita das plantas da área útil das parcelas $\left(4 \mathrm{~m}^{2}\right)$. As plantas foram trilhadas e os grãos foram pesados em balança de precisão e os dados obtidos foram corrigidos para $13 \%$ de umidade e transformados em $\mathrm{kg} / \mathrm{ha}$. O número de vagens por planta e número de grãos por vagem foram avaliados a partir de 5 plantas coletadas ao acaso dentro da área útil, ao passo que a massa de 100 sementes foi avaliada a partir dos grãos obtidos da área útil das parcelas, sendo os valores obtidos corrigidos para $13 \%$ de umidade.

Os dados obtidos foram submetidos à análise de variância e as médias dos tratamentos comparadas entre si pelo teste de Tukey a 5\% de probabilidade. Para a análise de variância os dados de percentagem de controle das plantas daninhas, em relação à testemunha, foram transformados em $\sqrt{\mathrm{x}+1}$, para homogeneização das variâncias. Também foram testados modelos matemáticos de regressão linear e não linear, usando o programa TableCurve, para expressar a relação entre níveis de controle da poaia-branca, rendimento e componentes de rendimento do feijoeiro.

\section{RESULTADOS E DISCUSSÃO}

Verifica-se na Tabela 2, que o melhor resultado no controle da poaia-branca, no momento da semeadura, foi obtido com a mistura de glyphosate $+2,4 \mathrm{D}$, com $40 \%$ de controle; porém, este resultado na prática é insatisfatório devido ao baixo nível de controle da infestante. De um modo geral pode-se constatar que no momento da semeadura o nível de controle da poaia-branca foi deficiente para todos os tratamentos testados, com um nível de controle inferior a $40 \%$. Isso devido ao fato de que os herbicidas testados apresentam como característica um modo de ação lento, o que justifica os resultados obtidos no momento da semeadura da cultura..

Aos 7 DDS o melhor resultado foi obtido com sulfosate, com $72 \%$ de controle sobre a poaia-branca, enquanto que o glyphosate CS e a aplicação seqüencial de sulfosate e paraquat/ diuron não diferiram significativamente entre si, embora o nível de controle para ambos os tratamentos $(56 \%)$ tenha sido insuficiente sobre a infestante.

Aos 18 DDS os melhores resultados foram obtidos com o sulfosate e glyphosate CS, que não diferiram estatísticamente entre si, apresentando 80 e $75 \%$ de controle, respectivamente. Os dados do presente trabalho, diferem dos obtidos por Marochi (1995), que verificou que herbicidas sistêmicos, isolados ou em misturas, foram ineficientes no controle da poaiabranca, embora o glyphosate tenha sido estatísticamente superior ao sulfosate. Quando estes tratamentos foram complementados com paraquat/diuron o nível de controle foi superior a $96 \%$. Verificou também que o paraquat/diuron foi o mais eficiente tratamento para controle de poaia-branca e que os resultados foram mais evidentes em aplicação seqüencial e que tais resultados, embora viáveis para controle de folhas largas, permitem rebrota de gramíneas, pelo que utilização de um herbicida sistêmico na primeira aplicação é mais recomendável.

Em um trabalho realizado por Theisen \& Andres (2000), os autores verificaram que o melhor resultado no con- 
Tabela 2. Percentagem visual de controle de poaia-branca (Richardia brasiliensis) com a aplicação dos herbicidas de manejo na cultura do feijoeiro. Fazenda Experimental Gralha Azul/PUCPR. Fazenda Rio Grande, PR. 1999/2000.

\begin{tabular}{|c|c|c|c|}
\hline \multirow{2}{*}{ Tratamento } & \multicolumn{3}{|c|}{ Controle $(\%)$} \\
\hline & Semeadura & $7 \mathrm{DDS}^{1}$ & 18 DDS \\
\hline Sulfosate & $29 \mathrm{~b}^{2}$ & $72 \mathrm{a}$ & $80 \mathrm{a}$ \\
\hline Glyphosate CS & $28 \mathrm{~b}$ & $57 \mathrm{~b}$ & $75 \mathrm{a}$ \\
\hline Sulfosate e paraquat/diuron ${ }^{3}$ & $22 \mathrm{c}$ & $56 \mathrm{~b}$ & $58 \mathrm{c}$ \\
\hline Glyphosate WG & $28 \mathrm{~b}$ & $44 \mathrm{c}$ & $66 \mathrm{~b}$ \\
\hline Glyphosate+2,4 D & $40 \mathrm{a}$ & $48 \mathrm{c}$ & $66 \mathrm{~b}$ \\
\hline Testemunha s/ herbicida & Od & $0 \mathrm{~d}$ & $0 \mathrm{~d}$ \\
\hline $\mathrm{F}$ & $582,2 * *$ & $802,4 * *$ & $2466,8 * *$ \\
\hline $\mathrm{CV}(\%)$ & 4,1 & 3,5 & 2,0 \\
\hline
\end{tabular}

${ }^{1}$ Dias depois da semeadura.

${ }^{2}$ Médias seguidas de mesma letra na vertical não diferem estatísticamente entre si pelo teste de Tukey a $5 \%$ de probabilidade.

${ }^{3}$ Aplicação seqüencial.

** Significativo a $1 \%$ de probabilidade.

trole da poaia-branca ocorreu com glyphosate WG a $1440 \mathrm{~g} /$ ha e.a., dispensando misturas com outros herbicidas ou adjuvantes.

Na prática, os produtores que utilizam o manejo com glyphosate + 2,4 D em aplicação única, em poaia-branca obtêm resultados médios de $40 \%$ de controle, o que conjugado a invernos quentes e baixas precipitações no início da primavera, tem dado menor condição de estabelecimento de culturas subseqüentes, devido a interferência da infestante e fitotoxicidade do 2,4 D (Oliveira, 1989).

Na Tabela 3 estão os resultados obtidos para rendimento e componentes do rendimento do feijoeiro. Verifica-se que os melhores rendimentos foram obtidos com os herbicidas sulfosate e glyphosate CS, que apresentaram 2092 e 2158 $\mathrm{kg} / \mathrm{ha}$, respectivamente, não diferindo estatísticamente entre si. Conforme dados da Tabela 2, verifica-se que estes mesmos tratamentos foram os que apresentaram os melhores resultados de controle da poaia-branca aos 18 DDS, proporcionando assim melhores condições para o estabelecimento inicial da cultura, devido a menor interferência inicial da poaiabranca, o que refletiu em melhor produção do feijoeiro.

Com relação aos componentes do rendimento, podese observar na Tabela 3 que para o número de vagens por planta houve diferenças significativas entre os tratamentos e que o melhor resultado foi obtido com sulfosate (16 vagens por planta), embora não tenha ocorrido diferença estatística deste tratamento em relação ao glyphosate CS (15,5 vagens por planta). Quanto número de sementes por vagem e massa de 100 sementes não houve diferenças significativas entre os tratamentos. Dentre as características agronômicas que com-

Tabela 3. Rendimento, número de vagens por planta, número de sementes por vagem e massa de 100 sementes, do feijoeiro submetido a diferentes manejos químicos. Fazenda Experimental Gralha Azul/PUCPR. Fazenda Rio Grande, PR. $1999 / 2000$.

\begin{tabular}{lcccc}
\hline \multicolumn{1}{c}{ Tratamento } & $\begin{array}{c}\text { Rendimento } \\
\text { (kg/ha) }\end{array}$ & $\begin{array}{c}\text { Número de } \\
\text { vagens/planta }\end{array}$ & $\begin{array}{c}\text { Número de } \\
\text { sementes/vagem }\end{array}$ & $\begin{array}{c}\text { Massa de 100 } \\
\text { sementes (g) }\end{array}$ \\
\hline Sulfosate & $2092 \mathrm{a}^{1}$ & $16,0 \mathrm{a}$ & 5,2 & 19,5 \\
Glyphosate CS & $2158 \mathrm{a}$ & $15,5 \mathrm{ab}$ & 5,1 & 18,6 \\
Sulfosate e paraquat/diuron & $1526 \mathrm{c}$ & $9,0 \mathrm{c}$ & 5,1 & 18,4 \\
Glyphosate WG & $1848 \mathrm{~b}$ & $11,7 \mathrm{bc}$ & 4,7 & 18,9 \\
Glyphosate+2,4 D & $1543 \mathrm{c}$ & $12,0 \mathrm{bc}$ & 4,9 & 18,8 \\
Testemunha s/ herbicida & $228 \mathrm{~d}$ & $4,7 \mathrm{~d}$ & 4,8 & 1,4 \\
\hline F & $950,1^{* *}$ & $25,0^{* *}$ & $0,4^{\mathrm{ns}}$ & $1,9^{\text {ns }}$ \\
CV $(\%)$ & 2,0 & 14,6 & 13,0 & 3,2 \\
\hline
\end{tabular}

${ }^{1}$ Médias seguidas de mesma letra na vertical não diferem estatísticamente entre si pelo teste de Tukey a 5\% de probabilidade.

* Significativo a $1 \%$ de probabilidade.

${ }^{\text {ns }}$ Não significativo. 

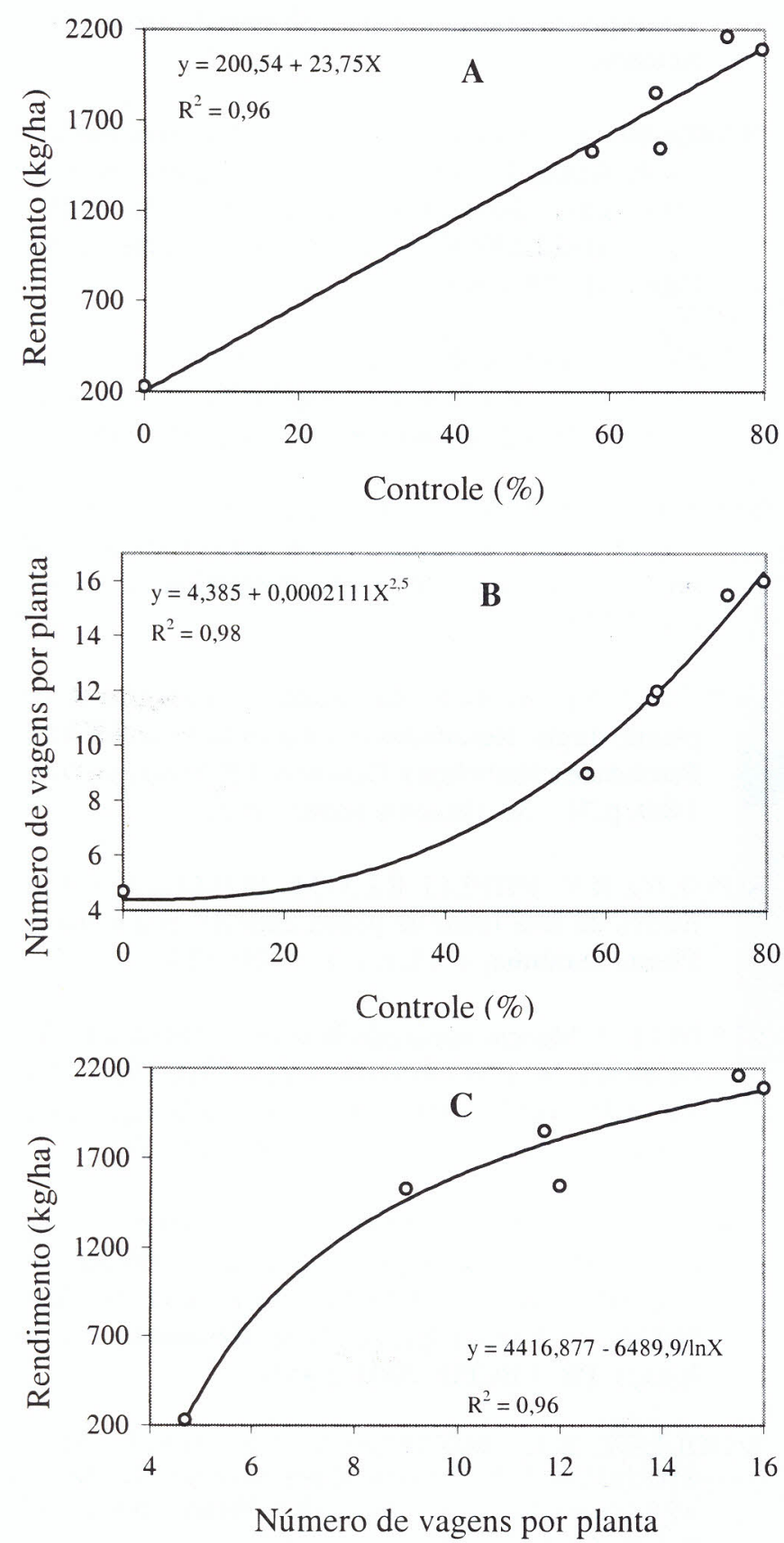

Figura 1. Relação entre: (A) níveis de controle da poaiabranca e rendimento de grãos, (B), número de vagens por planta e controle da poaia-branca, e (C) número de vagens por planta e rendimento de grãos, em função da aplicação dos herbicidas de manejo na cultura do feijoeiro em plantio direto. Fazenda Experimental Gralha Azul/ PUCPR. Fazenda Rio Grande, PR. 1999/2000.

põe os componentes do rendimento, o número de sementes por vagem e massa de 100 sementes são características definidas geneticamente, sendo assim menos influenciadas por fatores ambientais, seja de natureza biótica ou abiótica.

Na Figura 1 A encontram-se expostos, em forma gráfica, os resultados referentes à análise de regressão entre rendimento de grãos do feijoeiro e níveis de controle da poaiabranca, os quais mostram relação linear significativa, indicando que elevados rendimentos podem ser alcançados quando se obtém altos níveis de controle da infestante. A equação de regressão encontrada estima que se perdem $237,5 \mathrm{~kg} / \mathrm{ha}$ de grãos do feijoeiro para cada redução de $10 \%$ no grau de controle da poaia-branca.

Na Figura $1 \mathrm{~B}$, encontram-se os resultados da regressão não linear referentes à relação entre número de vagens por planta e níveis de controle da poaia-branca. Por ser uma espécie de difícil controle e promover intensa interferência competitiva, especialmente no início do ciclo do feijoeiro (Kissmann \& Groth, 1994; Ruedell, 2000), os resultados mostram que os maiores níveis de controle da infestante proporcionaram melhores condições para o crescimento e desenvolvimento do feijoeiro, apresentando assim um maior número de vagens por planta. Em estudo sobre a competição interespecífica de plantas daninhas na cultura do feijoeiro, Carvalho (1981) verificou que a interferência reduziu a produção e o número de vagens por planta no feijoeiro e que este foi o único componente do rendimento influenciado pela competição. Em outros trabalhos, constatou-se que o número de vagens por planta foi significativamente diminuído devido à interferência das plantas daninhas e que o número de grãos por vagem e massa de 100 sementes não sofreram reduções significativas, concluindo-se que o número de vagens por planta é o componente do rendimento mais sensível a interferência das plantas daninhas (Malik et al., 1993; Neary \& Majek, 1990; Ngouajio et al., 1997; Woolley et al., 1993).

Na Figura $1 \mathrm{C}$, encontram-se os resultados da regressão não linear referentes à relação entre rendimento de grãos e número de vagens por planta, mostrando que os tratamentos que proporcionaram um melhor controle da poaia-branca e um maior número de vagens por planta apresentaram também os melhores rendimentos de grãos.

\section{CONCLUSÕES}

Os melhores resultados no controle da poaia-branca foram obtidos aos 18 DDS com os herbicidas sulfosate e glyphosate CS, sendo que estes mesmos tratamentos foram os que apresentaram os melhores rendimentos de grãos. Com relação aos componentes do rendimento, só houve diferença significativa para número de vagens por planta, com o sulfosate apresentando o melhor resultado. Para os demais componentes não houve diferença significativa entre os tratamentos. De acordo com os modelos de regressão, houve uma relação significativa entre níveis de controle da poaiabranca, rendimento de grãos e componentes do rendimento do feijoeiro. 


\section{LITERATURA CITADA}

ADEGAS, F.S. Manejo integrado de plantas daninhas em plantio direto no Paraná. In: I SEMINÁRIO NACIONAL SOBRE MANEJO E CONTROLE DE PLANTAS DANINHAS EM PLANTIO DIRETO, 1. Passo Fundo, 1998. Resumos de Palestras. Passo Fundo, RS: Editora Aldeia Norte, 1998. p.17-26.

ALMEIDA, F.S. Controle de plantas daninhas em plantio direto. Londrina, PR: INSTITUTO AGRONÔMICO DO PARANÁ, 1991. 34 p. (Circular técnica nº 67).

BUZATTI, W.J. de S. Controle de plantas daninhas no sistema plantio direto na palha. In: Plantio Direto: atualização tecnológica. São Paulo, SP: Fundação Cargill/ Fundação ABC, 1999. p.97-111.

CARVALHO, D. A. Estudo sobre a competição específica de malerbas na cultura do feijoeiro. II. Efeito competitivo do capim marmelada (Brachiaria plantaginea) e picãopreto (Bidens pilosa), em diferentes densidades, sobre o "stand"final, produção de grãos e componentes primários da produção do feijoeiro (Phaseolus vulgaris L.). Ciência Prática, Lavras, v. 5, n. 2, p.138-143, 1981.

KISSMANN, K; GROTH, D. Plantas infestantes e nocivas. Tomo II. São Paulo, SP: BASF Brasileira, 1994. 603 p.

LORENZI, H. Manual de identificação e controle de plantas daninhas. 4 ed. Nova Odessa, SP: Editora Plantarum, 1991. $320 \mathrm{p}$.

LORENZI, H. Considerações sobre plantas daninhas no plantio direto. In: Plantio direto. Campinas, SP: Fundação Cargill, 1984. p.13-46.

MALIK, V.S.; SWANTON, C.J.; MICHAELS, T.E. Interaction of white bean (Phaseolus vulgaris L.) cultivars, row spacing and seedling density with annuals weeds. Weed Science, v. 14, n.1, p.62-68, 1993.

MAROCHI, A. I. Evaluation of chemical control methods for Richardia brasiliensis, in infested areas under notill system in the southern region of Brazil. In: ZAPP THE CHALLENGE OF THE NEW. Abstracts... São Paulo, SP, 1995. p.57 - 60 .

NEARY, P.E.; MAJEK, B.A. Commom cocklebur (Xanthium strumarium) interference in snap beans (Phaseolus vulgaris L.). Weed Technology, v.4, n.4, p.743-748, 1990.

NGOUAJIO, M.; FOKO, J.; FOUEJIO, D. The critical period of weed control in common bean (Phaseolus vulgaris L.) in Cameroon. Crop Protection, v. 16, n.2, p.127-133, 1997.

OLIVEIRA, V.F. Avaliação de tratamentos para manejo em plantio direto. Resultados de ensaios de verão 1988/89. Fertilidade e Herbologia. Carambeí, PR: Fundação ABC, 1989. p.34 - 36. (Boletim técnico no 3).

ROSSETO, R.R.; PITELLI, R.L.C.M.; PITELLI, R.A. Estimativa da área foliar de planta daninha: poaia branca Planta Daninha, v. 15, n.1, p.25-29, 1997.

RUEDELL, J. Manejo integrado de plantas daninhas no Sul do Brasil. In: ENCONTRO NACIONAL DE PLANTIO DIRETO NA PALHA, 7. Foz do Iguaçu, 2000 Resumos... Foz do Iguaçu, PR, 2000. p.56-63.

THEISEN, G.; ANDRES,A. Manejo de Richardia brasiliensis na implantação da cultura da soja. In: CONGRESSO BRASILEIRO DA CIÊNCIA DAS PLANTAS DANINHAS, 22. Foz do Iguaçu, 2000. Resumos... Foz do Iguaçu, PR: CBCPD, 2000. p.453.

WOOLLEY, B.L.; MICHAELS, T.E.; HALL, M.R.; SWANTON, C.J. The critical period of weed control in white bean (Phaseolus vulgaris L.). Weed Science, v.41, n.2, p.180-184, 1993. 